\title{
Model of Hydraulic Project Design Scheme Assessment Based on Information Entropy TOPSIS Model
}

\author{
Xiaoyu $\operatorname{Han}^{1, a)}$, Yingkui Guo ${ }^{2, b)}$, Saige $\mathrm{Li}^{2, \mathrm{c})}$
}

1. Yellow River Conservancy Technical Institute, Engineering Technology Research Center of Small

Watershed Conversancy University of Henan Province, Kaifeng 475004,China;

2.North China University of Water Resources and Electric Power,Zhengzhou450011,China; )

a)87633112@qq.com_b)2008hanxiaoyu@163.com_c)303807297@qq.com

Abstract. It is vital to build the assessment of scientific rational mathematical model which is key to optimally select the design schemes of hydraulic project. In particular, the model can analysis the weight of evaluation indexes and data mining. The paper put forth the Information entropy coupled TOPSIS model which can objectively calculate the weight of evaluate indexes and relatively close, then calculate the weight of scheme indexes and relatively close through the MATLAB R2013b. Finally, this model can determine the best scheme. Applying this method to evaluate the seepage prevention design schemes of city artificial lakes, it verifies the feasibility and operability of this method and its computation has been stable. Meanwhile, the method has valuable reference to the hydraulic engineering design schemes.

Keywords. design scheme optimal; coupled model; information entropy ; TOPSIS method

\section{Introduction}

In the process of water conservancy project design phase, different design science reasonable selection is an important factor to design a high standard. Water conservancy project plan optimization is the multi-target and multi-level optimization process, these messages are often part of the complete, there is only statistical information, cannot be directly as scheme evaluation information. Current design optimizing choose single more optimization method, such as the evaluation method based on extension theory ${ }^{[1][2]}$, grey clustering analysis and fuzzy comprehensive evaluation method ${ }^{[3]}$ has been used in the design optimization, but most of these models with a certain subjective weight assignment, the information is not complete and quantitative evaluation process accuracy is not high.

In this paper, through the establishment of Information Entropy IEN (Information Entropy) and TOPSIS coupling model, to establish the evaluation model of the evaluation index of the objective data mining, and the weight of each evaluation index objectively. The coupling model can effectively solve the objective quantitative evaluation index weight accuracy is not high and can't reflect the problems of communication between data information and practical solutions.

\section{IEN - TOPSIS coupling model}

IEN - TOPSIS coupling model of comprehensive evaluation system, the system is an important weight assignment, to determine the scheme close to ideal solution, determine the relative closeness steps, such as specific as follows:

Step 1: plan optimization evaluation system is established. To dimensionless processing of the evaluation data samples, for standardizing the scheme evaluation. Suppose $\mathrm{m}, \mathrm{n}$ assessment indexes, the decision matrix $X=\left(x_{i j}\right)_{m \times n}$. In accordance with the original data standardization method to transform:

$$
X_{i j}^{\prime}=\frac{X_{i j}-\bar{X}_{j}}{S_{j}}
$$

Among them, Average value $\bar{X}_{j}$ as an index $\mathrm{j}$ for the index values of the standard deviation of $\mathrm{j}$.

Then the different dimensional normalization processing and then complete the actual value to the transformation of the index value.

For extremely large indicators, such as the engineering effect, construction technology, investment, such as:

$$
\text { Type in the } \quad r_{i j}=\frac{x_{i j}}{x_{0 j}}=\frac{x_{i j}}{\max _{k}^{k} x_{k j}}, \max x_{i j}=x_{k 1} \vee x_{k 2} \vee \cdots \vee x_{k n}
$$

For very small indicators, such as the construction difficulties, environmental impact, such as: 
Type in the $\quad r_{i j}=\frac{x_{0 j}}{x_{i j}}=\frac{\min _{k} x_{i j}}{x_{i j}}, \min x_{i j}=x_{k 1} \wedge x_{k 2} \wedge \cdots \wedge x_{k n}$

Determine the ideal solution of normalized decision matrix $r_{j}^{*}$

$$
r_{j}^{*}=\left\{\begin{array}{l}
\max _{1 \leq i \leq m} r_{i j} j \in J^{+} \\
\min _{1 \leq i \leq m} r_{i j} j \in J^{-} \quad j=1,2, \ldots, n
\end{array}\right.
$$

Represents the ideal value of the $\mathrm{j}$ index . Among them

$$
J^{+}=(\text {Very large index }), J^{-}=(\text {Very small index })
$$

Step 2: Evaluation of the weight of the evaluation index. IEN on the program of data (such as investment, construction process, duration and other factors) information and evaluation of the weight of the weight ${ }^{[}{ }^{]}$, Taking into account the TOPSIS method to obtain the implied index weight from the index information, And the upper part weight value is integrated to obtain the final weight of each evaluation index $\omega_{i}$,IEN solves the weights of each evaluation index $\omega_{i}$

$$
\omega_{i}=\left(1+\frac{1}{L n} \sum_{i=1}^{m} f_{i j} \operatorname{Ln} f_{\mathrm{ij}}\right) / \sum_{i=1}^{n}\left(-\frac{1}{\operatorname{Ln}} \sum_{i=1}^{m} f_{i j} \operatorname{Ln} f_{\mathrm{ij}}\right)
$$

TOPSIS calculation of index weight $\omega_{j}$ :

$$
\omega_{j}=\left\{\left(\sum_{j=1}^{n} \frac{1}{\sum_{i=1}^{m}\left(r_{i j}-r_{j}^{*}\right)^{2}}\right) \cdot \sum_{i=1}^{m}\left(r_{i j}-r_{j}^{*}\right)^{2}\right\}^{-1}
$$

Coupling model using empowerment of the comprehensive weight of each evaluation index weight:

$$
\lambda_{j}=\frac{\omega_{i} \cdot \omega_{j}}{\sum_{j}^{n} \omega_{i} \cdot \omega_{j}}, j=1,2, \ldots, n
$$

Step 3: determine the ideal solution ${ }^{[5]}$.Using TOPSIS method for evaluation of the scheme $M_{i}$ in the relative optimal scheme evaluation index $X_{i j}$ and the relative optimal scheme ${ }^{M_{0}}$ between the evaluation index $x_{0 j}$ of correlation coefficient as follows:

$$
\xi_{i j}=\frac{\min _{i} \min _{j} n \Delta r_{i j}+\rho \max _{i} \max _{j} x \Delta r_{i j}}{\Delta r_{i j}+\rho \max _{i} \max _{j} x \Delta r_{i j}}
$$
In the formula $\Delta r_{i j}=\left|r_{0 j}-r_{i j}\right|, \rho$ is the distinguish coefficient, $\quad 0 \leq \rho \leq 1 \quad$ usually in the
form of $\rho=0.5$

Correlation is judging matrix weighted correlation matrix:

$$
Z=\left(\lambda_{j} \xi_{i j}\right)_{m \times n}
$$

Close to the ideal solution $V^{+}$is the attribute value with the candidate best value, close to the ideal solution $V^{-}$, on the other hand.

$V^{+}=\left[\left(\max \lambda_{j} \xi_{i j} / j \in J^{+}\right),\left(\min \lambda_{j} \xi_{i j} / j \in J^{-}\right)\right]=\left[\begin{array}{llll}z_{1}^{+} & z_{2}^{+} & \cdots & z_{n}^{+}\end{array}\right]$ 
$V^{-}=\left[\left(\min \lambda_{j} \xi_{i j} / j \in J^{+}\right),\left(\max \lambda_{j} \xi_{i j} / j \in J^{-}\right)\right]=\left[\begin{array}{llll}z_{1}^{-} & z_{2}^{-} & \cdots & z_{n}^{-}\end{array}\right]$

For extremely large index set in type $J^{+}, J^{-}$is very small index set.

Step 4: the IEN - TOPSIS coupling model of the relative closeness of each scheme, finally get the optimal design scheme ${ }^{[6]}$. Calculate European space distance of the program:

$$
\begin{aligned}
& D_{i}^{+}=\sqrt{\sum_{j=1}^{n}\left(z_{i j}-z_{j}^{+}\right)^{2}}, i=1,2, \ldots, m \\
& D_{i}^{-}=\sqrt{\sum_{j=1}^{n}\left(z_{i j}-z_{j}^{-}\right)^{2}}, i=1,2, \ldots, m
\end{aligned}
$$

Calculating relative closeness of the program:

$$
C_{i}=\frac{D_{i}^{-}}{D_{i}^{-}+D_{i}^{+}}, i=1,2, \ldots, m
$$

\section{Calculation and analysis}

Urban water system is the urban ecological civilization construction space of the precious and rare resources, through the water system space reasonable decorate and scheduling, formed by artificial lake waterfront ecological landscape area, to connect the river as the backbone of drainage network. Artificial lakes both flood control and drainage, water supply and drainage, landscape water and agricultural irrigation, and other functions, is the key to effective drainage engineering, and in the planning and construction of artificial lakes on its site selection and design of seepage control, water diversion, etc, needs a scientific and reasonable planning evaluation. Based on the seepage control design of artificial lake as an example, the established IEN - TOPSIS model to evaluate seepage design scheme.

By the area of engineering geological exploration data, the inside reveals the depth of drilling, the lake formation mainly for quaternary holocene alluvium (Q4al) and the upper pleistocene series alluvium (Q3al). Genetic types, according to the strata lithology and engineering geological

\begin{tabular}{|c|c|c|c|c|}
\hline $\begin{array}{c}\text { Soil layer } \\
\text { number }\end{array}$ & $\begin{array}{l}\text { Formation } \\
\text { lithology }\end{array}$ & Bottom elevation & $\begin{array}{l}\text { Layer thickness } \\
\text { (m) }\end{array}$ & $\begin{array}{c}\text { The permeability } \\
\text { coefficient } \mathrm{k}(\mathrm{cm} / \mathrm{s})\end{array}$ \\
\hline (1) & Artificial filled soil & & & \\
\hline (2) & In the silty loam & $75.47 \sim 79.03 \mathrm{~m}$ & $1.3 \sim 5.2$ & $9.0 \times 10-5$ \\
\hline (3) & Silt & $73.91 \sim 78.03 \mathrm{~m}$ & $1.0 \sim 5.9$ & $5.0 \times 10-3$ \\
\hline (4) & Heavy silty loam & $69.97 \sim 72.42 \mathrm{~m}$ & $3.2 \sim 6.1 \mathrm{~m}$ & $9.5 \times 10-5$ \\
\hline (5) & Fine sand & $66.81 \sim 68.91 \mathrm{~m}$ & $1.8 \sim 3.9 \mathrm{~m}$ & $7.5 \times 10-3$ \\
\hline (6) & Silty clay & $60.51 \sim 67.67 \mathrm{~m}$ & $6.3 \sim 8.4 \mathrm{~m}$ & $4.0 \times 10-6$ \\
\hline (7) & Silver sand & Not to call & & $9.0 \times 10-3$ \\
\hline
\end{tabular}
characteristics, the exploration strata are divided into 7 layer, specific as shown in table 1 :

Table 1 the layers of soil permeability index

By calculation and field monitoring observed, Artificial lakes leakage occurs mainly in the first 3 layer silty sand layer, the first 5 layer silty sand layer. Large amounts of water leakage, will increase the lake body running cost, it will also push up the area around the underground water level, caused 
the problem of immersion and salinization in some areas and affect the ecological environment. Therefore, must be carried out on the lake, seepage prevention treatment and seepage control body design should meet the requirements of lake run-time seepage control, and prevent the lake surrounding areas due to the rise of ground water caused by immersion salinization, at the same time, should also take into account the lake and groundwater circulation and exchange, seepage control design scheme in table 2.

Table 2 seepage control design

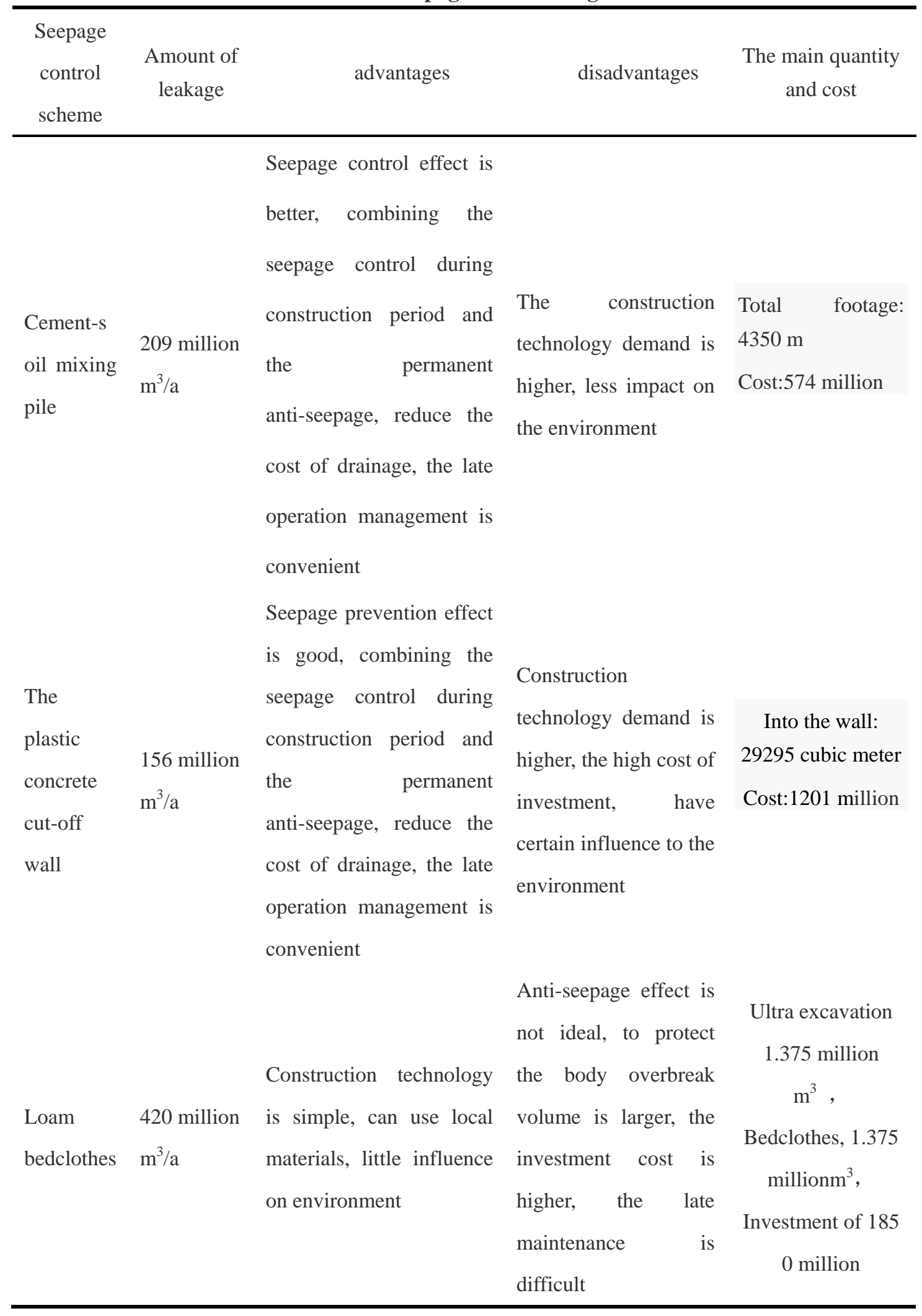


This article through the IEN - TOPSIS coupling model of artificial lakes seepage control design scheme for comprehensive analysis, final optimization scheme. Therefore, choose seven experts (relating to the hydrologic, structure, geological, economic, and so on various aspects) evaluation index of seepage control design scheme of alternative "efficiency, time limit for a project, construction technology, investment, construction difficulty, environmental impact", carried out in accordance with the 0 score $^{[7]}$, quantitative analysis was carried out on the design:

$\left[\begin{array}{llllll}93 & 87 & 91 & 89 & 88 & 90 \\ 85 & 89 & 94 & 81 & 73 & 82 \\ 91 & 82 & 87 & 86 & 79 & 89 \\ 93 & 84 & 79 & 88 & 90 & 85 \\ 89 & 80 & 79 & 82 & 81 & 90 \\ 79 & 83 & 91 & 84 & 85 & 78 \\ 88 & 87 & 81 & 79 & 91 & 83\end{array}\right]$ standardization$\left[\begin{array}{llllll}1.245 & 1.431 & 1.473 & 1.452 & 0.801 & 1.207 \\ 0.436 & 1.237 & 1.235 & 0.456 & 0.416 & 0.528 \\ 1.149 & 1.218 & 1.216 & 0.951 & 0.739 & 1.216 \\ 1.232 & 0.527 & 0.803 & 1.135 & 1.416 & 1.239 \\ 0.761 & 0.807 & 0.677 & 1.610 & 0.809 & 1.139 \\ 1.261 & 0.616 & 1.217 & 0.861 & 1.126 & 0.825 \\ 1.171 & 1.163 & 0.367 & 0.873 & 1.284 & 0.901\end{array}\right]$

IEN - TOPSIS coupling model to make use of MATLAB R2013B programming, according to the coupling model steps to solve the above evaluation matrix, get the weight of seepage control scheme and the relative closeness ${ }^{[8]}$ calculation and analysis of the matrix.

IEN the weights are obtained:

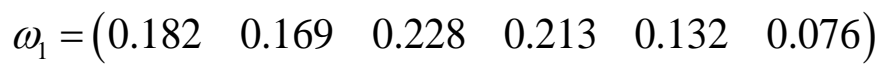

The seepage control design of three groups $M_{1}, M_{2}, M_{3}$, each scheme of quantitative indicators such as table 3

Table 3 three quantitative indicators

\begin{tabular}{ccccccc}
\hline $\begin{array}{c}\text { Package } \\
\text { number }\end{array}$ & $\begin{array}{c}\text { Work } \\
\text { efficiency }\end{array}$ & $\begin{array}{c}\text { Period } \\
\text { (month) }\end{array}$ & $\begin{array}{c}\text { The } \\
\text { construction } \\
\text { technology }\end{array}$ & $\begin{array}{c}\text { Investment } \\
\text { million } \\
\text { yuan }\end{array}$ & $\begin{array}{c}\text { The } \\
\text { constructi } \\
\text { on } \\
\text { difficulty }\end{array}$ & $\begin{array}{c}\text { The } \\
\text { environmen } \\
\text { tal impact }\end{array}$ \\
\hline$M_{1}$ & 0.91 & 15 & 0.89 & 574 & 0.82 & 0.70 \\
$M_{2}$ & 0.94 & 17 & 0.87 & 1201 & 0.85 & 0.75 \\
$M_{3}$ & 0.88 & 13 & 0.92 & 1850 & 0.71 & 0.65 \\
\hline
\end{tabular}

According to the data given in table 3 , the relative optimal design factors $\mathrm{M} 0$ index $\mathrm{M} 0=(0.94$ 130.875740 .710 .65 ) ,list the solution set of $\mathrm{M}$ on the properties of the Matrix.

TOPSIS method, the weight of each index is obtained:

$$
\omega_{i}=\left(\begin{array}{llllll}
0.362 & 0.211 & 0.217 & 0.051 & 0.098 & 0.061
\end{array}\right)
$$

Coupling model is obtained by using the index of the comprehensive weight:

$$
\lambda_{j}=\left(\begin{array}{llllll}
0.372 & 0.189 & 0.275 & 0.089 & 0.057 & 0.014
\end{array}\right)
$$

Three groups of solutions and the corresponding indexes multi-objective decision relevance evaluation matrix composed of:

$$
Z=\left[\begin{array}{llllll}
0.269 & 0.161 & 0.286 & 0.071 & 0.063 & 0.018 \\
0.351 & 0.188 & 0.174 & 0.044 & 0.037 & 0.007 \\
0.313 & 0.118 & 0.231 & 0.031 & 0.032 & 0.005
\end{array}\right]
$$


To solve the related evaluation matrix can be concluded that $\mathrm{V}-\mathrm{V}+$ ideal solution and negative ideal solution:

$$
\begin{aligned}
& V^{+}=\left[\begin{array}{llllll}
0.368 & 0.191 & 0.283 & 0.071 & 0.059 & 0.016
\end{array}\right] \\
& V^{-}=\left[\begin{array}{llllll}
0.267 & 0.134 & 0.185 & 0.031 & 0.030 & 0.005
\end{array}\right]
\end{aligned}
$$

IEN - TOPSIS model for calculating the various schemes of European space degree and relative distance:

$$
\begin{aligned}
& D^{+}=\left[\begin{array}{lll}
0.0973 & 0.1062 & 0.1052
\end{array}\right] \\
& D^{-}=\left[\begin{array}{lll}
0.1231 & 0.1189 & 0.0703
\end{array}\right] \\
& C_{i}=\left[\begin{array}{lll}
0.561 & 0.502 & 0.382
\end{array}\right]
\end{aligned}
$$

Through the analysis of the coupling model, we can see that the relative close of the scheme is 0.561 , which is the most reasonable in general. Therefore, the anti-seepage design scheme adopts the scheme one, and the coupling model is consistent with the actual result. In the process of actual evaluation, it is often difficult to find valid historical sample data. Therefore, it is the key to the evaluation of the model, and the evaluation result of the model is affected by the parameters. Based on the IEN-TOPSIS coupling model, this paper does not need to carry out sample training to the neural network from the objective weight and the calculation close degree, and it has a wide range of applicability, and the model construction idea is clear, easy to implement and operable.

\section{Conclusion}

Evaluation of water conservancy engineering design involves the problem complicated, factors to consider relevance is stronger, not only consider a single factor evaluation, establishing scientific and reasonable mathematical evaluation model has important practical significance. According to the uncertainty of design scheme of water conservancy projects as well as the characteristics of correlation between the evaluation index, based on IEN - TOPSIS coupling model for quantitative analysis of design scheme of each evaluation index. In addition, based on objective information entropy method to determine the index weight, avoid too much interference with human factors effectively, at the same time through the TOPSIS method for data mining analysis, weight assignment, to the comprehensive evaluation index weight assignment more objective and reasonable. IEN TOPSIS based coupling model for the comprehensive assessment of water conservancy engineering design scheme, the method meaning clear and coherent, evaluation conclusion conforms to the actual situation, has the very high reference value and research significance.

\section{ACKNOWLEDGMENTS}

This work was financially supported by Henan province science and technology research fund (142102310122、132102310320)、Yellow River Conservancy Technical Institute youth scientific research fund project (2016QNKY002).

\section{REFERENCES}

[1] Guo Shenglian, Zhang Jun, Guo Jing, etc. Of the han river basin flood forecasting system based on weather patterns. [J]. Journal of water conservancy and hydropower science and technology progress, 2009, 29 (3) : 1-5

[2] Wang Guangyue Niu Zhigeng, Wang Meng etc. Grey correlation approach for evaluation of foundation treatment of ideal solution. [J]. Journal of mathematics practice and understanding, 2011 (6) : 115-120 
[3] lifen, Meng Gang etc. The application of fuzzy comprehensive evaluation method in the stability of surrounding rock classification. [J]. Journal of wuhan university (engineering science), 2011, 44 (6) : 744-747

[4] Ding Kun,Jin Juliang , Zhang Libing, etc. Based on the information entropy of the sewage treatment plant planning reform decision-making evaluation projection pursuit model [J]. Water supply and drainage, 2010, 4 (5) : 166-170.

[5] Chen Hongyan . Improve the ideal solution and its application in the engineering bid evaluation. [J]. Journal of systems engineering theory method, 2004 (10) : 471-473

[6] Zhou Huijun , Jie Xiaoying, zhang Hao. Based on improved grey correlation analysis method of terminal design scheme optimization. [J]. Journal of Shanghai maritime university, 2011, 32 (3) : 11-15

[7] Huo Yingbao,Han Zhijun. Based on the generalized maximum entropy principle and genetic algorithm method to determine index weight study [J]. Journal of mathematical statistics and management, 2005, 24 (3) : 39-44, 50

[8] Jin Juliang ,Wu Yonglin , Wang Mingwu . The combination of urban flood control standard schemes optimization weight method $[\mathrm{J}]$. Journal of sichuan university (engineering science). $2004,36(4): 1-5$ 